\title{
Older Adults Vs Middle-Aged Adults: Heel Velocity
}

\author{
Sukwon Kim
}

\begin{abstract}
The objective of the present study was to evaluate heel contact velocity of middle-age adults and older adults. Ten adults ( 5 middle age adults and 5 older adults) were recruited from a local community. They were all physically healthy and not injured in the last 6 months. Their heel position data were collected during subsequent 5-minute walking on a straight track (15m long). The results indicated that heel contact velocity of middle-age adults were faster than that of older adults during their natural gait. The study concluded that middle-age adults' heel contact velocity could be faster suggesting that their slip propensity could be higher compared to older adults while walking on a leveled floor.
\end{abstract}

Keywords-HCV, Middle age, Older, Foot force

\section{INTRODUCTION}

For adults over 65 years of age, slips and falls are major health threat due to their dreadful effects of the quality of their life [1].

Older adults with falls experiences tended to be the bed-bound and subsequently performed less daily activities such as house works or/and family care [1]. And, they were less likely to participate in social activity resulting in functional and physical declines [2].

Horizontal foot force (shear force, Fh) at heel contact may be a cross product of foot mass and foot's horizontal acceleration. With a given body mass and the constant contact time during the heel contact phase of a gait cycle, horizontal heel contact velocity would be directly proportional to horizontal foot force (impulse-momentum relationship [3]). Heel slips or foot slips happened if the horizontal foot force was larger than the available friction of the floor at the heel contact phase of a gait cycle [4].

Age-associated muscular strength reduction was found [5]. Center for Disease Control(CDC) suggested that middle-age adults were vulnerable to injuries [6]. Middle-age adults were found to be at a higher risk of musculoskeletal injuries compared to older adults [7].

Manuscript received July 20, 2020

Sukwon Kim, Department of Physical Education, Jeonbuk National University, Jeonju, Jeollabukdo, South Korea, 82-63-270-2860 (email:rockwall@jbnu.ac.kr).
There have been a little study looking in the heel contact velocity of middle-age adults even though middle-age adults were very vulnerable to adult disease and muscular skeletal diseases such as obesity, high blood pressure, diabetes, MSDs etc.

The present study was to compare heel contact velocity of older adults to that of middle-age adults.

\section{Method}

\section{A. Participants}

Ten adults from local community participated. Five were classified in older adults and another five were classified in middle-age adults. They were recruited from a local community.

They had no history of musculoskeletal injuries in the previous 6 months prior to the examinations. Older adults were all over 65 years of age and middle-age adults ranged from 40 to 51 years of age (Table 1).

Table 1: Age, Height, Weight of Two Groups

\begin{tabular}{|c|c|c|c|}
\hline Group & Age(years) & $\begin{array}{c}\text { Height }(\mathrm{cm} \\
)\end{array}$ & $\begin{array}{c}\text { Weight }(\mathrm{kg} \\
)\end{array}$ \\
\hline Middle-age & 46.5 & 179.2 & 78.7 \\
\hline Older & 71.3 & 176.6 & 73.4 \\
\hline
\end{tabular}

\section{B. Procedure}

One heel marker was place on the skin at the calcaneus bone of the right foot. They were instructed to initiate walking by standing with feet together. In order for examiners to access proper heel contact velocity of all adults, a force plate was used to identify the heel-contact instance during a gait cycle.

The position data of the heel marker was evaluated using eight-camera Prime 17W system (NaturalPoint, Inc, DBA Optitrack). Position data were sampled and recorded at $120 \mathrm{~Hz}$. Ground reaction forces during heel contact phase were sampled at a rate of $1200 \mathrm{~Hz}$.

They walked for about 5 minutes. When their right feet consistently stroke on the force plate, position data were collected for 1 seconds. They were instructed to walk as natural as possible. 


\section{Heel contact velocity}

The heel contact was identified when the vertical ground reaction force from a force plate (AMTI, \#4767, Type OR-6-7-1000, AMTI, INC. USA) was larger than 7 newton. The instant horizontal heel contact velocity $(\mathrm{HCV})$ was computed using the formula:

$\mathrm{HCV}=\left[\mathrm{X}_{(\mathrm{i}+1)}-\mathrm{X}_{(\mathrm{i}-1)}\right] / 2 \triangle \mathrm{t}$

$\mathrm{X}$ : heel position in horizontal direction

i: frame number

\section{Results}

One-way ANOVA results suggested that there was a significant difference ( $p=0.02, F=7.7$, Table 2$)$ in $\mathrm{HCV}$ between older adults and middle-age adults. The results indicated that $\mathrm{HCV}$ in middle age adults was higher than that in older adults (Figure 1).

Table 2: Data and ANOVA Summary in HCV of Two Groups

\begin{tabular}{|c|c|c|c|}
\hline \multicolumn{4}{|c|}{ Data Summary } \\
\hline Groups & N & Mean & SD \\
\hline Middle-Age Adults & 5 & 87.84 & 14.00 \\
\hline Older Adults & 5 & 64.29 & 12.88 \\
\hline
\end{tabular}

\begin{tabular}{|ccc|c|c|c|}
\hline \multicolumn{7}{c}{ ANOVA Summary } & & \\
\hline Source & $\begin{array}{c}\text { Degrees } \\
\text { of } \\
\text { Freedom } \\
\text { DF }\end{array}$ & $\begin{array}{c}\text { Sum of } \\
\text { Squares }\end{array}$ & $\begin{array}{c}\text { Mean } \\
\text { Square }\end{array}$ & F-Stat & P-Value \\
\hline $\begin{array}{c}\text { Between } \\
\text { Groups } \\
\text { Within }\end{array}$ & 1 & 1386.04 & 1386.04 & 7.65 & 0.024 \\
$\begin{array}{c}\text { Groups } \\
\text { Total: }\end{array}$ & 8 & 1449.17 & 181.146 & & \\
\hline
\end{tabular}

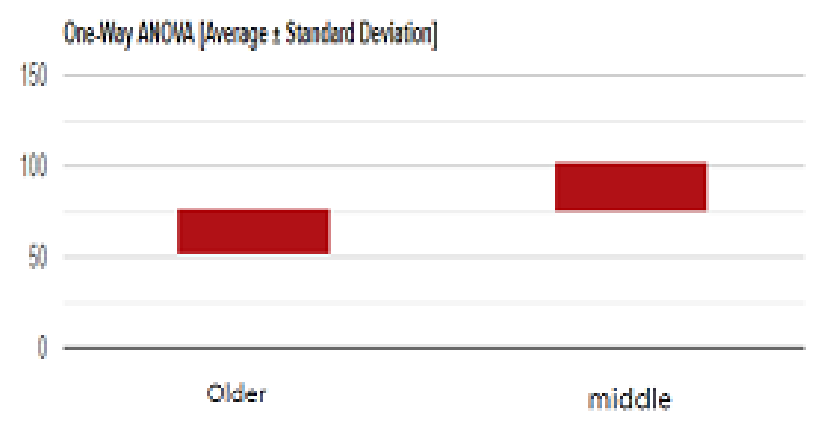

Fig 1: One-Way ANOVA (Mean and SD)

\section{Discussion}

The study objective was to compare HCV between middle age adults and older adults while walking on the leveled floor. Leg strength measures from a previous study suggested that middle age adults were not different from older adults [6]. The results from the study [6] may be suggesting that middle age adults' HCV should be similar to older adults' HCV because muscular strength should be proportionally associated with $\mathrm{HCV}[8,9]$. In the present study, HCVs of middle age adults were higher than that of older adults. This could suggest that leg muscular strength level was not the only factor in predicting $\mathrm{HCV}$ while walking. In future, there should be some study looking into factors influencing $\mathrm{HCV}$.

\section{Conclusion}

The study concluded that middle age adults' HCV was not different from older adults' HCV.

\section{RESEARCh QUESTION}

1. What will be other factors influencing HCV velocity besides age factor?

2. Why middle-age adults' HCV is higher than older adults?

3. Will middle-age adults' slip propensity be higher than older adults?

\section{ACKNOWLEDGEMENT}

This research was supported by "Research Base Construction Fund Support Program" funded by Jeonbuk National University in 2019 2020.

\section{REFERENCES}

[1] H. Huang, M. Gau, W. Lin, and Kernohan, Assessing risk of falling in older adults. Public Health Nursing 20:5;399-411.

[2] J. Judge, 2003, Balance training to maintain mobility and prevent disability, Am J Prev Med, 25, 150-156.

[3] C. Irvine, 1986. Evaluation of the effect of contact-time when measuring floor slip resistance, Journal of Testing and Evaluation, 1, 19-22.

[4] N. Sprince, H. Park, C. Zwerling, P. Whitten, C. Lynch, L. Burmeister, K. Thu, P. Gillette, M. AlavanjaRisk factors for low back injury among farmers in lowa: a case-control study nested in the agricultural health study, Journal of Occupational and Environmental Hygiene, 4 (2007), pp. $10-16$

[5] CDC, Workers Health Chartbook 2004, Figure 2-39, Distribution of MSD cases and all nonfatal injury and illness cases involving days away from work in private industry by age

[6] S. Kim, T. Lockhart, C. Nam, Leg strength comparison between younger and middle-age adults, International Journal of Industrial Ergonomics, 2010, 40(3);315-32.

[7] S. Kim, T. Lockhart $10 \%$ front load carriage on the likelihood of slips and falls Industrial Health, 46 (2008), 32-39

[8] U. Kuruganti, Philip Parker, Jeremy Rickards, Maureen Tin gleyStrength and muscle coactivation in older adults after lower limb strength training International Journal of Industrial Ergonomics, 36 (9) (2006), 761-766.

[9] T. Lockhart, J. Smith, J. Woldstad, Effects of aging on the biomechanics of slips and falls Human Factors, 47 (4) (2005), 708-729 